\title{
Fluorinated carbonates as new diluents for extraction and separation of $f$-block elements
}

Article

Accepted Version

Distler, P., Mindová, M., John, J., Babain, V. A., Alyapyshev, M. Y., Tkachenko, L. I., Kenf, E. V., Harwood, L. M. and Afsar, A. (2020) Fluorinated carbonates as new diluents for extraction and separation of f-block elements. Solvent Extraction and Ion Exchange, 38 (2). pp. 180-193. ISSN 1532-2262 doi: https://doi.org/10.1080/07366299.2019.1708004 Available at https://centaur.reading.ac.uk/88704/

It is advisable to refer to the publisher's version if you intend to cite from the work. See Guidance on citing.

To link to this article DOI: http://dx.doi.org/10.1080/07366299.2019.1708004

Publisher: Informa UK Limited

All outputs in CentAUR are protected by Intellectual Property Rights law, including copyright law. Copyright and IPR is retained by the creators or other copyright holders. Terms and conditions for use of this material are defined in the End User Agreement. 


\section{CentAUR}

Central Archive at the University of Reading

Reading's research outputs online 
Fluorinated Carbonates as New Diluents for Extraction and Separation of $f$-Block Elements

Petr Distler, ${ }^{a}$ Miriam Mindová, ${ }^{a}$ Jan John, ${ }^{a}$ Vasilij A. Babain,,${ }^{b}$ Mikhail Yu.

Alyapyshev, ${ }^{\mathrm{b}}$ Lyudmila I. Tkachenko, ${ }^{\mathrm{c}}$ Ekaterina V. Kenf, ${ }^{\mathrm{c}}$ Laurence M.

Harwood $^{\mathrm{d}}$ and Ashfaq Afsar ${ }^{\mathrm{d}}$

${ }^{a}$ Department of Nuclear Chemistry, Czech Technical University, Prague, Czech

Republic, ${ }^{b}$ Laboratory of Sensors, ITMO University, Saint Petersburg, Russian

Federation, ' Khlopin Radium Institute, Saint Petersburg, Russian Federation,

${ }^{d}$ Department of Chemistry, University of Reading, Reading, United Kingdom 


\section{Fluorinated Carbonates as New Diluents for Extraction and Separation of f-Block Elements}

The fluorinated carbonate BK-1 solvent was studied as a diluent in extraction systems with different extracting agents - CMPO, THDGA, CyMe 4 -BTBP and $\mathrm{CyMe}_{4}-\mathrm{BTPhen}$, which are the most promising molecules for separation of minor actinides and lanthanides. Dependence of the extraction properties of the system on the concentrations of $\mathrm{HNO}_{3}$ or extracting compound, kinetics of trivalent metal extraction and extraction of the ions by neat diluent (without the addition of extracting agent) were investigated. Based on the obtained results, BK-1 is a promising candidate diluent for $f$ block metal separation.

Keywords: separation; $f$-block elements; fluorinated carbonates; $N$ - and $O$-extracting compounds

\section{Introduction}

The irradiated nuclear fuel from nuclear power plants is highly radiotoxic, which is caused mainly by the transuranic elements it contains [1]. The major transuranic constituents, uranium and plutonium can be recovered in the PUREX process. Then, from the PUREX raffinate, the trivalent minor actinides and trivalent lanthanides may be co-extracted by the DIAMEX process. After these processes, European research programmes have developed the SANEX process, which selectively removes the trivalent minor actinides, Am and Cm, from the lanthanides for subsequent transmutation to non-radioactive elements or short-lived radionuclides in Generation IV reactors or dedicated ADT transmuters [2]. Various methods have been developed for reprocessing, with most processes being based on liquid-liquid extraction using different extracting compounds, mainly from the nitric acid solutions. [3] 
Hydrocarbons are traditionally used as the diluent for extracting agents in radiochemical technology. However, the loading capacity of polar ligands in hydrocarbons is usually limited and, as a result, third phase formation and precipitation can occur. For example, polar ligands such as diamides of diglycolic acid have a tendency toward third phase formation when n-dodecane is used as a diluent [4-6]. The third phase appears when 0.2 mol/L TODGA/n-dodecane solvent is contacted with 4 mol/L nitric acid, particularly in the presence of high concentrations of extracted metal ions [4].

As an alternative to saturated hydrocarbons, heavy halogenated diluents $\left(\rho_{\text {diluent }}>\right.$ $\left.\rho_{\text {water }}\right)$ were tested, mainly chlorinated short-chain hydrocarbons. The main advantage of these diluents was their higher density than water, because at high separated metal loadings the density of solvents based on diluents with low density can exceed the density of the aqueous phase which results in the reversal of the phases and severe complications of the separation processes. However, those chlorinated hydrocarbons such as hexachlorobutadiene, tetrachloroethylene or tetrachloromethane were found to suffer from different disadvantages such as corrosion problems, toxicity of the off-gasses, and volatility $[7,8]$. They were also found to be sensitive to ionizing radiation with some degradation products being miscible with or soluble in aqueous phase. [9]

One of the classes of perspective diluents that could help to overcome the draw-backs of hydrocarbons and chlorinated hydrocarbons is polar fluorinated solvents. Polar fluorinated diluents have several advantages over hydrocarbons, such as higher chemical and radiation stabilities and lower fire risk. For example, aromatic polar diluents, such as FS-13 (phenyl trifluoromethyl sulfone) and F-3 (meta-nitrobenzotrifluoride) with low viscosity and good chemical stability are promising diluents not only for CMPO [10,11], but also for diamides of diglycolic acid [12] and amides of $N$-heterocyclic dicarboxylic acids [13]. Data on the stability 
of the irradiated $\mathrm{CyMe}_{4}$-BTBP and $\mathrm{CyMe}_{4}$-BTPhen ligands in FS-13 indicates their higher stability in the FS-13 diluent than observed earlier in cyclohexanone-based diluents $[14,15]$.

A new class of polar fluorinated diluents - carbonates of fluorinated alcohols has been recently proposed as a possible alternative for hydrocarbons [16]. Carbonates of 2,2,3,3tetrafluoropropan-1-ol (BK-1) and 2,2,3,3,4,4,5,5-octafluoropentan-1-ol (BK-2) were synthesized at the Perm branch of FSUE “Applied Chemistry”, Perm, Russia. They have high boiling points, high densities and low solubilities in water. In Table 1, the properties of these diluents are compared with some previously used diluents. Particular among the advantages of these new diluents are their chemical stability and, in many cases, high polarity. Polar diluents increase the loading capacity of the organic phase and reduce probability of a third phase formation.

The aim of this work was to investigate the extraction of actinides and lanthanides from nitric acid solutions by selected extractants, dissolved in BK-1 as diluent and to compare the results with the performance of these ligands in more common diluents - F-3 for CMPO and THDGA, and octanol or cyclohexanone for $\mathrm{CyMe}_{4}$-BTBP and CyMe $4-\mathrm{BTPhen}$. BK-1 has been chosen for the present study as it has a lower viscosity compared to BK-2.

\section{Experimental}

CMPO was purchased from the group of Prof. Kalchenko at the Institute of Organic Chemistry, Kiev, Ukraine. THDGA was synthesized at the St-Petersburg State University. Polar fluorinated diluent BK-1 was synthesized in the Perm branch of FSUE “Applied Chemistry", Perm, Russia [19]. Polar fluorinated diluent F-3 was purchased from the Vekton company, St-Petersburg. The extracting compounds, CyMe 4 -BTBP and $\mathrm{CyMe}_{4}-\mathrm{BTPhen}$, were synthesized at the University of Reading, in the group of Prof. Harwood. The structures of extracting agents used are presented in Table 2. 
For the experiments with CMPO and THDGA, the ${ }^{241} \mathrm{Am}$ stock solution was obtained by dissolution of $\mathrm{AmO}_{2}$ in $\mathrm{HNO}_{3}$ followed by Am purification on a DOWEX-50 cation exchange resin. Am in $0.1 \mathrm{~mol} / \mathrm{L} \mathrm{HNO}_{3}$ was absorbed on the resin, washed several times with $0.1 \mathrm{~mol} / \mathrm{L} \mathrm{HNO}_{3}$, and eluted with $5 \mathrm{~mol} / \mathrm{L} \mathrm{HNO}_{3}$. Americium hydroxide was then precipitated by adding sodium hydroxide, washed, redissolved in $1 \mathrm{~mol} / \mathrm{L} \mathrm{HNO}_{3}$ and used as the working solution. The ${ }^{152} \mathrm{Eu}$ tracer solution was purchased from JSC Isotop (St-Petersburg, Russia) and used as supplied without further purification. Chemically pure nitric acid was used for solution preparation. Aqueous solutions for extraction of lanthanides were prepared from a multielement standard solution of lanthanides (VWR International, ARISTAR Multiple Elements Set 82025-926).

For the experiments with $\mathrm{CyMe}_{4}-\mathrm{BTBP}$ and $\mathrm{CyMe}_{4}$-BTPhen, the stock solution of ${ }^{241} \mathrm{Am}$ was prepared by dissolving americium oxide (Isotope Products Cesio s.r.o. Praha) in 2 $\mathrm{mL}$ of $5 \mathrm{~mol} / \mathrm{L} \mathrm{HNO}_{3}$ and the working solution was prepared by dilution of $20 \mu \mathrm{L}$ of the stock solution by $1 \mathrm{~mL}$ distilled water. The stock solution of ${ }^{152} \mathrm{Eu}$ was prepared by appropriate dilution of a commercial europium chloride preparation (REu-2, Polatom) in $2 \mathrm{~mL}$ of 0.001 mol/L $\mathrm{HNO}_{3}$ and the working solution was prepared by dilution of $5 \mu \mathrm{L}$ of the stock solution by $2.5 \mathrm{~mL} 0.001 \mathrm{~mol} / \mathrm{L} \mathrm{HNO}_{3}$. The stock solution of ${ }^{244} \mathrm{Cm}$ was prepared by dissolving curium nitrate (TENEX Russia) in $2 \mathrm{~mL}$ of $0.01 \mathrm{~mol} / \mathrm{L} \mathrm{HNO}_{3}$ and the working solution was prepared by dilution of $20 \mu \mathrm{L}$ of the stock solution by $1 \mathrm{~mL} 0.001 \mathrm{~mol} / \mathrm{L} \mathrm{HNO}_{3}$.

The aqueous phases for the experiments were prepared by labelling the nitric acid solutions (0.001-5 mol/L) with the working solutions of ${ }^{241} \mathrm{Am}$ and ${ }^{152} \mathrm{Eu}$. In the experiments with $\mathrm{CyMe}_{4}$-BTBP and $\mathrm{CyMe}_{4}-\mathrm{BTPhen}{ }^{244} \mathrm{Cm}$ was also added. The organic phases were prepared by dissolving the extracting compounds in the polar fluorinated diluent BK-1 or F-3 to the required concentration. 
The extraction experiments with THDGA and CMPO were carried out in $5 \mathrm{~mL}$ polypropylene vials; wherein $1 \mathrm{~mL}$ of organic phase and $1 \mathrm{~mL}$ of aqueous phase were placed and the vials vigorously agitated at room temperature $\left(21 \pm 1^{\circ} \mathrm{C}\right)$. Kinetics of extraction by CMPO and THDGA are rapid; in preliminary experiments, it was demonstrated that equilibrium was achieved in 2 minutes. Therefore, the standard agitation time for these solvents was 3 minutes. Phases were separated after a short centrifugation for 5-10 min, and aliquots $(0.4 \mathrm{~mL})$ were taken for analysis. The distribution ratios of ${ }^{241} \mathrm{Am}$ and ${ }^{152} \mathrm{Eu}$ were determined radiometrically. For activity measurements a DeskTop InSpector-1270 scintillation $\gamma$-spectrometer with a well-type NaI-detector $51 \times 51 \mathrm{~mm}$ " Canberra' Co was used.

In the whole lanthanide series extraction studies, the distribution ratios were determined from the results of analyses performed by ICP-MS method using ELAN $^{\odot}$ DRC-e ICP-MS (Perkin Elmer, USA). In this case, the initial aqueous phases contained 14 metals (La, Ce, Pr, Nd, Sm, Eu, Gd, Tb, Dy, Ho, Er, Tm, Yb, Lu) in nitric acid of the appropriate concentration. For common lanthanide extraction experiments, the concentration of each metal in initial solution was $10^{-5} \mathrm{~mol} / \mathrm{L}$. All experiments were carried out at least in triplicate.

In the experiments with $\mathrm{CyMe}_{4}-\mathrm{BTBP}$ and $\mathrm{CyMe}_{4}$-BTPhen, the dependence of extraction properties of the system on varying concentrations of $\mathrm{HNO}_{3}$ was investigated. A 4 mmol/L solution of $\mathrm{CyMe}_{4}$-BTPhen or $\mathrm{CyMe}_{4}$-BTBP was contacted with the aqueous phase (0.001-0.1-1-2-4 mol/L $\mathrm{HNO}_{3}$ ) in 1:1 ratio and shaken for a 1 hour on a Heidolph Multi Reax shaker at $1800 \mathrm{rpm}$. After shaking, the phases were centrifuged for 1 minute at $6000 \mathrm{rpm}$ on a Hettich, EBA 20 centrifuge. Due to the higher density of BK-1 compared to the usual hydrocarbon diluents used for such studies, the organic phase was at the bottom and the aqueous at the top. After phase separation, $10 \mu \mathrm{L}$ aliquots of organic and aqueous phase were 
taken on stainless steel planchets and two $150 \mu \mathrm{L}$ aliquots into plastic vials for the alpha or gamma measurements, respectively.

Before measurements on the alpha spectrometer, the samples on the stainless steel planchets were at first evaporated in the open, and then the planchets were heated in a flame until the glowed dull red, to minimize the residues. After cooling, the planchets were measured on an alpha spectrometer ORTEC® OCTETE Plus Integrated Alpha-Spectroscopy System (EG\&G, Ortec, USA). For gamma measurements, the walls of the plastic vials containing the $150 \mu \mathrm{L}$ aliquots were washed with $1 \mathrm{~mL}$ of water (aqueous phase) or octanol (organic phase). These vials were then measured on a gamma spectrometer EG\&G Ortec with PGT HPGe detector.

In the next part of the study, the kinetics of metal extraction from $1 \mathrm{~mol} / \mathrm{L} \mathrm{HNO}_{3}$ by 1 $\mathrm{mmol} / \mathrm{L}$ solution of $\mathrm{CyMe}_{4}-\mathrm{BTPhen}$ or $\mathrm{CyMe}_{4}-\mathrm{BTBP}$ were investigated. The kinetics were studied for 6 different shaking times over a period of 15 - 180 minutes. After contacting, the procedure was the same as described above for determining the dependence of extraction properties of the system on varying concentrations of $\mathrm{HNO}_{3}$, with the exception that $200 \mu \mathrm{L}$ of solution was taken for the gamma measurements. Finally, extraction of metals by the neat diluent BK-1 (no extractant) was studied. Diluent BK-1, as the organic phase, was contacted in a 1:1 ratio with five various concentrations of $\mathrm{HNO}_{3}(0.001-4 \mathrm{~mol} / \mathrm{L})$ spiked with the working solutions of $\mathrm{Am}, \mathrm{Cm}$ and $\mathrm{Eu}$. The shaking time was 1 hour. After shaking, the measurement process was exactly the same as for the kinetics experiments.

The extraction results thus obtained were evaluated for the following quantities:

Distribution ratio of metal M:

$$
D(\mathrm{M})=\frac{c_{\mathrm{org}}}{\epsilon_{\mathrm{aq}}} \cong \frac{I_{\text {org }}}{I_{\mathrm{aq}}}
$$


Extraction percentage:

$$
\% E=\frac{100 \cdot D}{1+D}
$$

where $c_{\text {org }}$ resp. $c_{\text {aq }}$ is concentration of metal ion in the organic resp. aqueous phase, and $I_{\mathrm{org}}$, resp. $I_{\mathrm{aq}}$ are measured count rates, $D\left(\mathrm{M}_{1}\right)$, resp. $D\left(\mathrm{M}_{2}\right)$ is distribution ratio of metal $\mathrm{M}_{1}$, resp. $\mathbf{M}_{2}$. The errors given in the figures are $1 \sigma$ and are based on the counting statistics, only.

It should be noted here that any interpretation of separation factor values must take into account also the values of distribution ratios. For efficient separation of two metals, one $D$ must be higher than 1 and the second $D$ lower than 1 . For systems where both values of $D$ are higher (or lower) than 1 , this condition can often be met by modifying the extraction conditions (e.g. concentration of the extractant, acidity / $\mathrm{pH}$, temperature etc.).

\section{Results and discussion}

\section{Extraction properties of CMPO}

In the extraction studies of Am(III) and Eu(III) from nitric acid solution with CMPO solutions in polar fluorinated diluent BK-1, the metal distribution ratios were found to increase in the range from 0.5 to $2 \mathrm{~mol} / \mathrm{L} \mathrm{HNO}_{3}$ (Figure 1). A further increase of aqueous phase acidity (up to $5 \mathrm{~mol} / \mathrm{L} \mathrm{HNO}_{3}$ ) led to a decrease of metal extraction. CMPO extracts Am(III) better than $\mathrm{Eu}(\mathrm{III})$, with $\mathrm{Am} / \mathrm{Eu}$ separation factor $\left(S F_{\mathrm{Am} / \mathrm{Eu}}\right)$ values decreasing from 2 to 1.3 with increasing nitric acid concentration. Decreasing $D$-values from $2 \mathrm{~mol} / \mathrm{L} \mathrm{HNO}_{3}$ can be explained by the extraction of $\mathrm{HNO}_{3}$ into the organic phase. 
The results of metal extraction from $3 \mathrm{~mol} / \mathrm{L}$ nitric acid as a function of CMPO concentration in BK-1 are presented in Figure 2. The calculated solvation numbers are 2.5 for both Am and Eu. Such values of solvation numbers can be explained by formation of two types of species in the organic phase: $\mathrm{MeL}_{2}\left(\mathrm{NO}_{3}\right)_{3}$ and $\mathrm{MeL}_{3}\left(\mathrm{NO}_{3}\right)_{3}$, where L represents CMPO.

The results of the study of lanthanides extraction are presented in Figure 3. The lanthanide extraction pattern is the same for all studied nitric acid concentrations: the distribution ratios firstly increase, then decrease with decreasing metal ion radius from $\mathrm{Sm}$ to Lu. The extraction ability of CMPO towards Ce, $\mathrm{Pr}$ and $\mathrm{Nd}$ is the same and, towards La, somewhat lower than towards Ce.

The extractions of lanthanides with CMPO in two different fluorinated polar diluents (F-3 and BK-1) were compared (Figure 4). The extraction ability of CMPO in BK-1 to trivalent metals is lower than when F-3 is used as a diluent.

In an additional experiment aimed at the determination of the behaviour of these systems at higher metal loadings, it was demonstrated that it is possible to achieve the theoretical capacity of organic phase (Me : CMPO ratio $1: 3)$ without formation of precipitates or the third phase.

\section{Extraction properties of THDGA}

In the extraction studies of Am and Eu from $0.5-5 \mathrm{~mol} / \mathrm{L}$ nitric acid solution with THDGA solutions in polar fluorinated diluent BK-1, the extraction ability of THDGA was found to increase with increasing nitric acid concentration. The maximal metal distribution ratios were achieved for extraction from 4 mol/ $\mathrm{L} \mathrm{HNO}_{3}$ (Figure 5). THDGA extracts Eu better than Am, as is typical for diglycolamides [5]. 
The results of metal extraction from $3 \mathrm{~mol} / \mathrm{L}$ nitric acid as a function of THDGA concentration in BK-1 are presented in Figure 6. The calculated solvation numbers are 2.75 for both Am and Eu. Such values of solvation numbers can be explained by formation of two types of species in the organic phase: $\mathrm{MeL}_{2}\left(\mathrm{NO}_{3}\right)_{3}$ and $\mathrm{MeL}_{3}\left(\mathrm{NO}_{3}\right)_{3}$ ( $\mathrm{L}$ represents THDGA) but the species with metal: ligand ratio as 1:3 is predominant.

The results of the study of lanthanides extraction are presented in Figure 7. The distribution ratios increase with decreasing metal ion radius from $\mathrm{La}$ to $\mathrm{Tb}$ and they change very little for the remaining heavier ones. The extraction of lanthanides with THDGA in two different polar diluents (F-3 and BK-1) was also compared (Figure 8). The extraction ability of THDGA in both diluents is very close.

The results show, that for a $0.1 \mathrm{~mol} / \mathrm{L}$ solution of THDGA in BK-1, the selectivity for the neighbouring pairs of light lanthanides is rather good (separation factors for $S F_{\mathrm{Ce} / \mathrm{La}}=$ 2.41; $S F_{\mathrm{Pr} / \mathrm{Ce}}=2.06 ; S F_{\mathrm{Nd} / \mathrm{Pr}}=2.16$ and $\left.S F_{\mathrm{Nd} / \mathrm{Sm}}=5.7\right)$. This means that this system is promising for group separation of all heavy lanthanide (Sm - Lu) from the light lanthanides.

\section{Extraction properties of $N$-donor ligands}

\section{$\operatorname{Am}(I I I) / E u(I I I)$ separation}

For the extraction system containing $\mathrm{CyMe}_{4}-\mathrm{BTBP}$, the values shown in Figure 9 were found. The general shape of the curves corresponds to the behaviour of this extractant in other diluents [e.g. 20,21] - after a slow increase of $D$ with the $\mathrm{HNO}_{3}$ concentration (the $D(\mathrm{Am})$ at $0.1 \mathrm{~mol} / \mathrm{L} \mathrm{HNO}_{3}$ seems to be an outlier), the curves pass a maximum and then $D$ decreases. This decrease has been earlier assigned to the extraction of $\mathrm{CyMe}_{4}-\mathrm{BTBP}$ with nitric acid at high $\mathrm{HNO}_{3}$ concentrations that results in decreasing the extracting compound concentration and thus also decreases the extraction of the metal ion [20]. The maximum distribution ratios were found at $2 \mathrm{~mol} / \mathrm{L} \mathrm{HNO}_{3}$; the respective values being $D_{\max }(\mathrm{Am})=148 \pm 67$ and $D_{\max }(\mathrm{Eu})$ 
$=0.93 \pm 0.01$. The published value achieved under similar conditions $\left(5 \mathrm{mmol} / \mathrm{L} \mathrm{CyMe}_{4}-\right.$

BTBP, $2 \mathrm{~mol} / \mathrm{L} \mathrm{HNO}_{3}$ ) in another polar diluent, cyclohexanone, was $D_{\max }(\mathrm{Am})=12.2$ [21].

Hence, it can be seen that new diluent BK-1 achieves much higher $D(\mathrm{Am})$ values than the previously tested diluent. To compare with a non-polar diluent, in octanol $(10 \mathrm{mmol} / \mathrm{L}$ CyMe 4 -BTBP, $\left.0.01 \mathrm{~mol} / \mathrm{L} \mathrm{HNO}_{3}+0.99 \mathrm{~mol} / \mathrm{L} \mathrm{NaNO}_{3}\right) D(\mathrm{Am})$ was only 0.35 mainly due to slow kinetics in octanol [22].

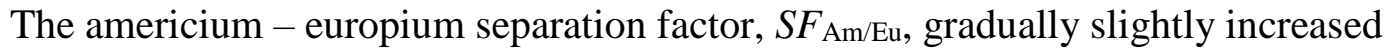
with the increasing $\mathrm{HNO}_{3}$ concentration. The highest value of $S F_{\mathrm{Am} / \mathrm{Eu}}$ was achieved in 4 $\mathrm{mol} / \mathrm{L} \mathrm{HNO}_{3}$ and was equal to $S F_{\mathrm{Am} / \mathrm{Eu}}=164 \pm 22$. Again, when compared with the data obtained in cyclohexanone, the maximum $S F_{\mathrm{Am} / \mathrm{Eu}}=124 \pm 7$ was achieved in $1 \mathrm{~mol} / \mathrm{L} \mathrm{HNO}_{3}$; so it is lower than in BK-1. Similarly, in the system with octanol the values of $S F_{\mathrm{Am} / \mathrm{Eu}}$ were also significantly lower than in BK-1 and did not exceed the value of $S F_{\mathrm{Am} / \mathrm{Eu}}=20$ [21].

The behaviour of the extraction system containing $\mathrm{CyMe}_{4}-\mathrm{BTPhen}$ is shown in Figure 10. As expected, the shapes of the dependences are similar to the previous described $\mathrm{CyMe}_{4}-$ BTBP system. The most striking difference is the shift of the maxima of the curves towards lower $\mathrm{HNO}_{3}$ concentrations. The values of distribution ratios for both elements, Am(III) and $\mathrm{Eu}(\mathrm{III})$, are also significantly higher than with $\mathrm{CyMe}_{4} \mathrm{BTBP}$ over the whole nitric acid concentration range investigated. The Am(III) distribution ratios reached the highest values $\left(D_{\max }(\mathrm{Am})>630\right.$ and $\left.D_{\max }(\mathrm{Am})>590\right)$ in $1 \mathrm{~mol} / \mathrm{L}$ and $2 \mathrm{~mol} / \mathrm{L} \mathrm{HNO}_{3}$, respectively. For $\mathrm{Eu}(\mathrm{III})$, the $D$ reached the highest value $\left(D_{\max }(\mathrm{Eu})=12.8+0.3\right)$ at as low as $0.1 \mathrm{~mol} / \mathrm{L} \mathrm{HNO}_{3}$. For a comparison, the published values achieved under similar conditions $\left(1 \mathrm{~mol} / \mathrm{L} \mathrm{HNO}_{3}, 5\right.$ $\mathrm{mmol} / \mathrm{L} \mathrm{CyMe} 4-\mathrm{BTPhen})$ in cyclohexanone were $D(\mathrm{Am})=447 \pm 113, D(\mathrm{Eu})=10.2 \pm 0.2$; resulting in $S F_{\mathrm{Am} / \mathrm{Eu}}=44 \pm 12$ [14]. In a non-polar diluent, the maximum distribution ratio values for $1 \mathrm{mmol} / \mathrm{L} \mathrm{CyMe}_{4}$-BTPhen in octanol, were reached for $\mathrm{Am}(\mathrm{III})$ in $3 \mathrm{~mol} / \mathrm{L} \mathrm{HNO}_{3}$ $\left(D_{\max }(\mathrm{Am})=23.9 \pm 2.3\right)$ while for $\mathrm{Eu}(\mathrm{III})$ the maximum was observed in $1 \mathrm{~mol} / \mathrm{L} \mathrm{HNO}_{3}$ 
$\left(D_{\max }(\mathrm{Eu})=0.120 \pm 0.004\right)$. In the first case, the separation factor value was $S F_{\mathrm{Am} / \mathrm{Eu}}=206 \pm$ 22, in the second case in $1 \mathrm{~mol} / \mathrm{L} \mathrm{HNO}_{3} S F_{\mathrm{Am} / \mathrm{Eu}}=156 \pm 10$ [20].

Similarly to the system with $\mathrm{CyMe}_{4}-\mathrm{BTBP}$, the $S F_{\mathrm{Am} / \mathrm{Eu}}$ values increase with increasing $\mathrm{HNO}_{3}$ concentration. For $4 \mathrm{mmol} / \mathrm{L} \mathrm{CyMe} 4-\mathrm{BTPhen}$ dissolved in BK-1, the highest value of $S F_{\mathrm{Am} / \mathrm{Eu}}=405 \pm 87$ was achieved in $4 \mathrm{~mol} / \mathrm{L} \mathrm{HNO}_{3}$. This value is approximately 2.5 higher than the value obtained in the CyMe $4-B T B P$ system.

\section{$\operatorname{Am}(I I I) / C m(I I I)$ separation}

As can be seen in Figure 11 and Figure 12 and as it could be expected, there is no significant difference between the extraction of $\mathrm{Am}(\mathrm{III})$ and $\mathrm{Cm}$ (III) by either $\mathrm{CyMe}_{4}-\mathrm{BTBP}$ or $\mathrm{CyMe}_{4}-$ BTPhen dissolved in BK-1. Extraction of Am(III) is slightly preferred to the extraction of $\mathrm{Cm}$ (III) over the whole nitric acid concentration range. Within experimental error, the values of $S F_{\mathrm{Am} / \mathrm{Cm}}$ also do not depend significantly on the $\mathrm{HNO}_{3}$ concentrations. The highest values of $\mathrm{Am}(\mathrm{III}) / \mathrm{Cm}(\mathrm{III})$ separation factors measured were $S F_{\max }(\mathrm{Am} / \mathrm{Cm})=4.1 \pm 1.1$ for the system with CyMe $4-\mathrm{BTBP}$ (in $0.1 \mathrm{~mol} / \mathrm{L} \mathrm{HNO}_{3}$ ) or $S F_{\max }(\mathrm{Am} / \mathrm{Cm})=6.0 \pm 1.1$ for the system with $\mathrm{CyMe}_{4}$-BTPhen. However, considering the large uncertainties of the $S F_{\mathrm{Am} / \mathrm{Cm}}$, their realistic values can be estimated as the average over the whole nitric acid concentration ranges, being $S F_{\mathrm{Am} / \mathrm{Cm}}=2.6 \pm 0.6$ for the system with $\mathrm{CyMe}_{4}-\mathrm{BTBP}$ or $S F_{\mathrm{Am} / \mathrm{Cm}}=2.4 \pm 0.8$ for the system with $\mathrm{CyMe}_{4}-\mathrm{BTPhen}$. These values are slightly lower when compared with the results achieved under similar conditions in other diluents. For $1 \mathrm{mmol} / \mathrm{L} \mathrm{CyMe} 4-\mathrm{BTPhen}$ in octanol, the highest value was $S F_{\mathrm{Am} / \mathrm{Cm}}=3.3 \pm 0.2$ in $6 \mathrm{~mol} / \mathrm{L} \mathrm{HNO}_{3}$. In cyclohexanone, this value was almost twice that $\left(S F_{\mathrm{Am} / \mathrm{Cm}}=5.9 \pm 1.0\right)$ in $0.5 \mathrm{~mol} / \mathrm{L} \mathrm{HNO}_{3}$, but the concentration of $\mathrm{CyMe}_{4}$-BTPhen was $5 \mathrm{mmol} / \mathrm{L}$ [20]. 


\section{Kinetics of metal extraction}

The extraction of $\mathrm{Am}(\mathrm{III}), \mathrm{Eu}(\mathrm{III})$, and $\mathrm{Cm}$ (III) from $1 \mathrm{~mol} / \mathrm{L} \mathrm{HNO}_{3}$ by $1 \mathrm{mmol} / \mathrm{L}$ $\mathrm{CyMe}_{4}-\mathrm{BTBP}$ in BK-1 as a function of contact time of the phases was tested. It was shown that, for all the radionuclides, equilibrium was achieved after about 45 minutes of shaking. For Am(III), the extraction percentage was higher than $90 \%$ in the equilibrium, while for $\mathrm{Eu}(\mathrm{III})$ the percentage of extraction did not exceed $20 \%$. The extraction of Am(III) and $\mathrm{Eu}(\mathrm{III})$ is shown in Figure 13.

Similar data are presented in Figure 14 for the $\mathrm{CyMe}_{4}-\mathrm{BTPhen}$ system, where a striking difference in the rates of extraction was observed for $\mathrm{Am}(\mathrm{III})$ and $\mathrm{Cm}(\mathrm{III})$, and $\mathrm{Eu}(\mathrm{III})$. While the extraction of $\mathrm{Am}(\mathrm{III})$ and $\mathrm{Cm}(\mathrm{III})$ is very fast (equilibrium was achieved in less than 15 minutes of shaking, with a percentage of extraction over $99 \%$ ), the extraction of $\mathrm{Eu}(\mathrm{III})$ is rather slow and the equilibrium is not achieved even after 3 hours of contacting the phases. Even though differences in the rates of extraction of $\mathrm{Am}(\mathrm{III})$ and $\mathrm{Eu}(\mathrm{III})$ have been observed earlier [20] and were explained by the differences in the mass transfer rates [23], the reasons for such large differences as observed in this study are unclear at this moment and will require a more detailed investigation.

The kinetics of Am(III) and Cm(III) extraction have been previously studied in detail under similar extraction conditions (e.g. $1 \mathrm{mmol} / \mathrm{L} \mathrm{CyMe}$-BTPhen and the same mixing rate of $1,800 \mathrm{rpm}$ ) in a range of diluents [20]. When comparing the time-dependence of the values for $D(\mathrm{Am})$, striking differences can be seen among the various systems. In the system with octanol and $1 \mathrm{~mol} / \mathrm{L} \mathrm{HNO}_{3}$, the system does not achieve equilibrium even after 2 hours of shaking. By adding toluene to the octanol (40:60, octanol:toluene) and using $4 \mathrm{~mol} / \mathrm{L} \mathrm{HNO}_{3}$, the extraction even slower and equilibrium was achieved only after 4 hours of shaking. On the contrary, when using cyclohexanone as diluent and $0.5 \mathrm{~mol} / \mathrm{L} \mathrm{HNO}_{3}, \mathrm{Am}(\mathrm{III})$ extraction was rapid and the equilibrium was attained within few minutes of shaking [21]. 
Comparing these data with the new BK-1-based system, it can be said that BK-1 has faster kinetics than non-polar systems, but still slower kinetics than observed with cyclohexanone. On the other hand, BK-1 has other advantages useful for industrial use compared to cyclohexanone as already mentioned.

\section{Extraction of metals by the neat diluent BK-1}

Solvent extraction by the neat diluent without addition of any extracting agent is an important property of any liquid-liquid extraction system. Among others, it may play a decisive role in the limiting values of achievable separation factors. This is why this parameter was investigated for the neat BK-1 diluent.

The results obtained show that the values of the distribution ratios of all elements [Am(III), $\mathrm{Eu}(\mathrm{III})$, and $\mathrm{Cm}(\mathrm{III})]$ in any of the experiments performed did not exceed the value of $D=0.003$, which was the lower limit of detection in our study. This means that, in absence of the extraction component, the polar fluorinated diluent BK-1 does not extract trivalent An and $\mathrm{Ln}$ from the aqueous phase at any $\mathrm{HNO}_{3}$ concentration in the range of $0.001-4 \mathrm{~mol} / \mathrm{L}$ $\mathrm{HNO}_{3}$. This is an important finding, because some previously tested diluents, such as cyclohexanone, considered for the same processes, extract Am(III) and Eu(III) in the absence of any added extractant, especially at higher concentrations of $\mathrm{HNO}_{3}$ [21].

\section{Conclusions}

New solvent systems based on polar fluorinated diluents - BK-1 or F-3 and four prospective ligands have been studied for their ability to distinguish between trivalent minor actinides and lanthanides. It was shown, that the main trends in extraction selectivity remain the same regardless of the diluent used. However, the extraction ability of the ligand can change depending on diluent properties. 
The influence of BK-1 on extraction abilities of CMPO and THDGA is different but it was demonstrated that both ligands can be used in BK-1 for extraction of americium and lanthanides. It is also noteworthy that, under these conditions, THDGA shows promising selectivity in separation of light lanthanides - La-Nd, and very low selectivity for heavy lanthanides.

For the case of the separation of lanthanides and actinides by $N$-donor ligands, the new fluorinated diluent BK-1 offers an alternative to other polar (cyclohexanone) or non-polar (octan-1-ol) diluents used so far. The maximum $D(\mathrm{Am})$ ratios obtained with BK-1 are significantly higher than in cyclohexanone and an enhanced americium - europium separation factor can also be achieved. When compared with their performance in octanol-based solvents, the performance of both the $\mathrm{CyMe}_{4}-\mathrm{BTBP}$ and $\mathrm{CyMe}_{4}-\mathrm{BTPhen}$ ligands in BK-1 diluents is also superior and yields almost double Am distribution ratios and americium europium separation factors [20]. An important finding is that even though the metal extraction into BK-1 is slower than when using cyclohexanone, it is much faster than extraction using the non-polar octanol diluent or its mixture with toluene. Furthermore, no extraction of metal ions was observed into the neat BK-1 diluent in the absence of extracting ligand. This gives this diluent an important advantage over diluents such as cyclohexanone. To conclude, the results presented herein clearly demonstrate the advantages of the polar fluorinated diluents, making the BK-1 diluent a prospective diluent for $f$-block metal separation. It offers a solution of how to overcome some of the disadvantages of other diluents such as third-phase formation, partial solubility in nitric acid, flammability, extraction of metal ions by the neat diluent and slow kinetics encountered with previously studied systems. Also, its radiation stability is expected to significantly exceed that of the previously proposed chlorinated hydrocarbons. The radiation stability of BK-1 will be studied in detail in the next phase. 


\section{Acknowledgments}

This research has been supported by the Center for advanced applied science, project number CZ.02.1.01/0.0/0.0/16_019/0000778, granted by the Ministry of Education, Youth and Sports of the Czech Republic, the Grant Agency of the Czech Technical University in Prague, grant No.

SGS18/192/OHK4/3T/14, the Horizon 2020 Euratom Research and Innovation Programme of the European Union GENIORS, grant No. H2020-755171, and by the Government of Russian Federation, Grant 074-U01. 


\section{References}

[1] Modolo, G.; Geist, A.; Miguirditchian, M. Minor actinide separations in the reprocessing of spent nuclear fuels. In Reprocessing and Recycling of Spent Nuclear Fuel, Robin Taylor (Ed); Elsevier: Boston, 2015, 245-287.

[2] Salvatores, M.; Palmiotti, G. Radioactive waste partitioning and transmutation within advanced fuel cycles: Achievements and challenges. Prog. Part. Nucl. Phys., 2011, 66, 144-166.

[3] Aneheim, E.; Ekberg, Ch.; Fermvik, A.; Foreman, M. R. St. J.; Retegan, T.; Skarnemark, G. A TBP/BTBP-based GANEX Separation Process. Part 1: Feasibility. Solvent Extr. Ion Exch., 2010, 28(4), 437-458, DOI: 10.1080/07366299.2010.480930.

[4] Tachimori, S.; Sasaki, Y.; Suzuki, S. Modification of TODGA-n-dodecane solvent with a monoamide for high loading of lanthanides(III) and actinides(III). Solvent Extr. Ion Exch., 2002, 20, 687-699, DOI: 10.1081/SEI-120016073.

[5] Zhu, Z.-X.; Sasaki, Y.; Suzuki, H.; Suzuki, S.; Kimura, T. Cumulative study on solvent extraction of elements by N,N,N',N'-tetraoctyl-3-oxapentanediamide (TODGA) from nitric acid into n-dodecane. Anal. Chim. Acta, 2004, 527, 163-168, DOI: 10.1016/j.aca.2004.09.023.

[6] Sasaki, Y.; Sugo, Y.; Suzuki, S.; Kimura, T. A method for the determination of extraction capacity and its application to N,N,N'N'-tetraalkylderivatives of diglycolamidemonoamide/n-dodecane media. Anal. Chim. Acta, 2005, 543, 31-37.

[7] Horwitz, E. P.; Martin, K. A.; Diamond, H.; Kaplan, L. Extraction of Am from Nitric Acid by Carbamoylphosphoryl Extractants: The Influence of Substituents on the selectivity of Am over Fe and Selected Fission Products. Solvent Extr. Ion Exch., 1986, 4:3, 449-494, DOI: 10.1080/07366298608917877.

[8] Puzikov, E.A.; Kudinov, A. S.; Blazheva, I. V.; Sytnik, L. V.; Shishkin, D. N.; Goletskii, N. D.; Zilberman, B.Ya.: Mathematical Modeling of Extraction of Nitric Acid, Actinides, and Fission Products into 30\% TBP in Halogenated Diluents Using A.M. Rozen's Model. Radiochemistry, 2017, 59(2), 143-151. DOI: 10.1134/S1066362217020060.

[9] Egorov, G. F.; Afanas'ev, O. P.; Zilberman, B. Y.; Makarychev-Mikhailov, M. N. Radiation-Chemical Behavior of TBP in Hydrocarbon and Chloro Hydrocarbon Diluents under Conditions of Reprocessing of Spent Fuel from Nuclear Power Plants. Radiochemistry. 2002, 44, 151-156. DOI: 10.1023/A:1019619212460.

[10] Babain, V. A.; New solvents with fluorinated diluents for high level wastes processing, Proc. of Int. Conf. SESTEC, 2008.

[11] Babain, V. A.; Alyapyshev, M. Y.; Kiseleva, R. N. Metal extraction by N, N'-dialkyl-N, N'-diaryl-dipicolinamides from nitric acid solutions. Radiochim. Acta, 2007, 95(4), 217 223, DOI: 10.1524/ract.2007.95.4.217.

[12] Alyapyshev, M. Y.; Babain, V. A.; Eliseev, I.; Kenf, E.; Tkachenko, L. New polar fluorinated diluetns for diamide extractants. J. Radioanal. Nucl. Chem., 2016, 310(2), 785-792.

[13] Alyapyshev, M. Y.; Babain, V. A. Amides of heterocyclic carboxylic acids as novel extractants for high-level waste treatment. Tkachenko, L. I; Radiochem, 2014, 56(6), 565574. 
[14] Distler, P.; Kondé, J.; John, J.; Hájková, Z.; Švehla, J.; Grüner, B. Characterization of Solvents Containing CyMe4-BTPhen in Selected Cyclohexanone-Based Diluents after Irradiation by Accelerated Electrons. Nukleonika - Int. J. Nucl. Res., 2015, 60(4), 885891, DOI: 10.1515/nuka-2015-0123.

[15] Kondé, J.; Distler, P.; John, J.; Švehla, J.; Grüner, B.; Bělčická, Z. Radiation influencing of the extraction properties of the CyMe4-BTBP and CyMe4-BTPhen solvents with FS13. Procedia Chem., 2016, 2, 174-181, DOI: 10.1016/j.proche.2016.10.025.

[16] Babain, V. A.; Alyapyshev, M. Y.; Voronaev, I. G.; Logunov, M. V; Voroshilov, Y. A.; Trefilov, I. G. Extraction mixture for extraction of actinides from nitric acid solutions. RU patent 2620 583, May 29, 2017.

[17] Maksimov, B. N. Inductrial fluororganic products, presented in part at International Exhibition - KHIMIA, St. Petersburg, 1996.

[18] Vohlídal, J.; Julák, A.; Štulík, K.; Chemické a analytické tabulky. Grada, 1999.

[19] Alyapyshev, M. Yu.; Babain, V. A.; Bakhmutov, Yu. L.; Voronaev, I. G.; Kozen, A. L. Method for preparing fluorine-containing dialkylcarbonates, RU patent 2646 226, March 02, 2018.

[20] Lewis, F. W.; Harwood, L. M.; Hudson, M. J.; Afsar, A.; Laventine, D. M.; Št’astná, K.; John, J.; Distler, P. Separation of the Minor Actinides Americium(III) and Curium(III) by Hydrophobic and Hydrophilic BTPhen Ligands: Exploiting Differences in their Rates of Extraction and Effective Separations at Equilibrium. Solvent Extr. Ion Exch., 2018, 36:2, 115-135, DOI: 10.1080/07366299.2018.1429358.

[21] Distler, P.; Špendliková, I.; John, J.; Harwood, L. M.; Hudson, M. J.; Lewis, F. W. Influence of diluent alkyl substitution on the extraction of $\mathrm{Am}(\mathrm{III})$ and $\mathrm{Eu}(\mathrm{III})$ by a $6,6^{\prime}$ bis(1,2,4-triazin-3-yl)-2,2'-bipyridine ligand dissolved in alkylated cyclohexanone diluents. Radiochim. Acta, 2012, 100:10, 747-752, DOI: 10.1524/ract.2012.1949.

[22] Panak, P. J.; Geist, A. Complexation and Extraction of Trivalent Actinides and Lanthanides by Triazinylpyridine N-Donor Ligands. Chem. Rev., 2013, 113, 1199-1236, DOI: $10.1021 / \mathrm{cr} 3003399$.

[23] Distler, P.; Stamberg, K.; John, J.; Harwood, L. M.; Lewis, F. W. Modelling of the Am(III) - Cm(III) kinetic separation effect observed during metal ion extraction by bis(1,2,4)-triazine ligands. Sep. Sci. Technol., 2018, 53(2), 2779-285, DOI: 10.1080/01496395.2017.1384017. 
Table 1. Structures and comparison of the properties ( $B p=$ boiling point, $d=$ density, $\eta=$ viscosity) of the new diluents with some previously used diluents.

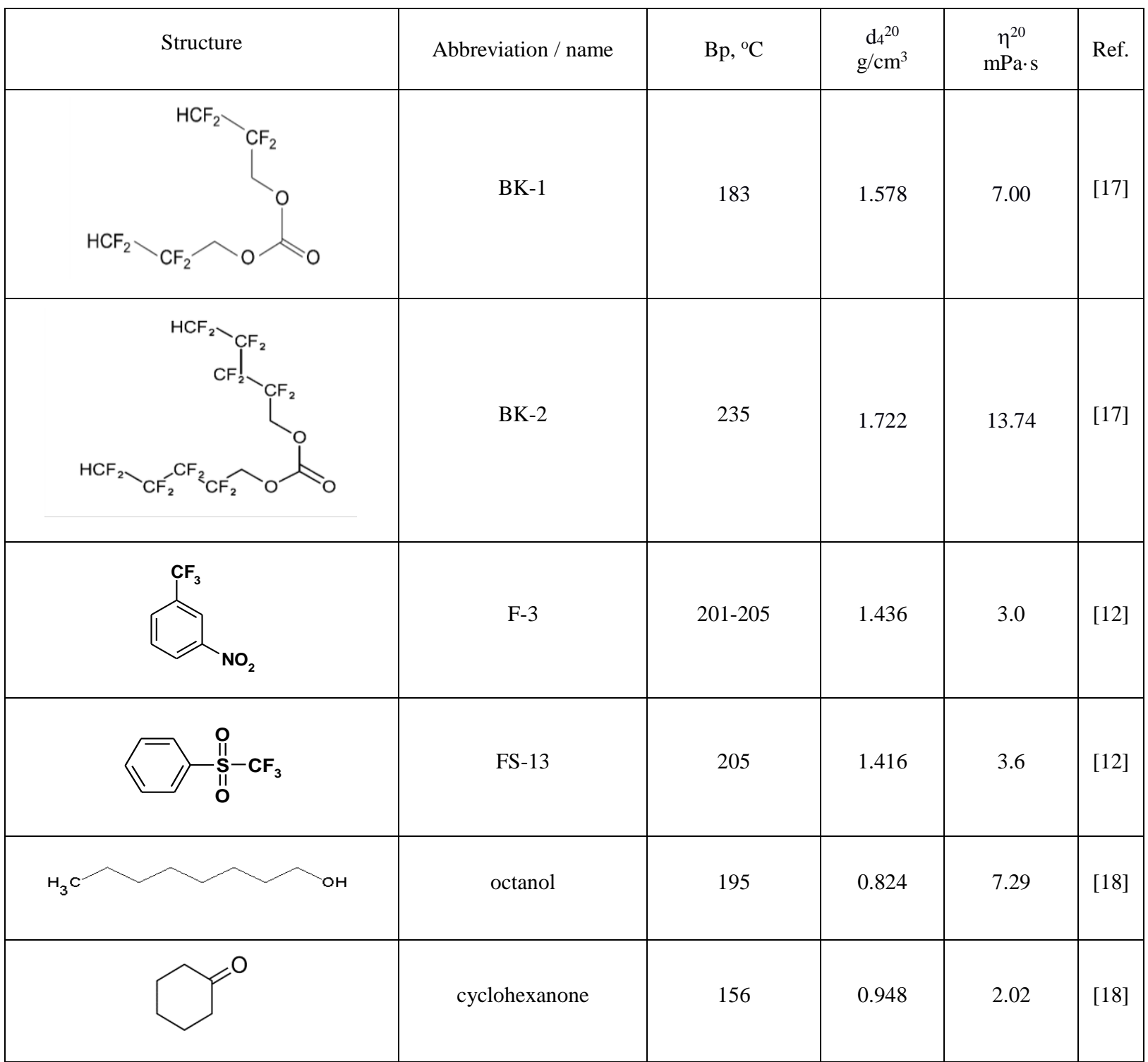


Table 2. Structures of extracting agents and diluents

\begin{tabular}{|c|c|}
\hline Name and abbreviation \\
\hline octyl(phenyl)-N,N-diisobutylcarbamoyl \\
methylphosphine oxide (CMPO)
\end{tabular}




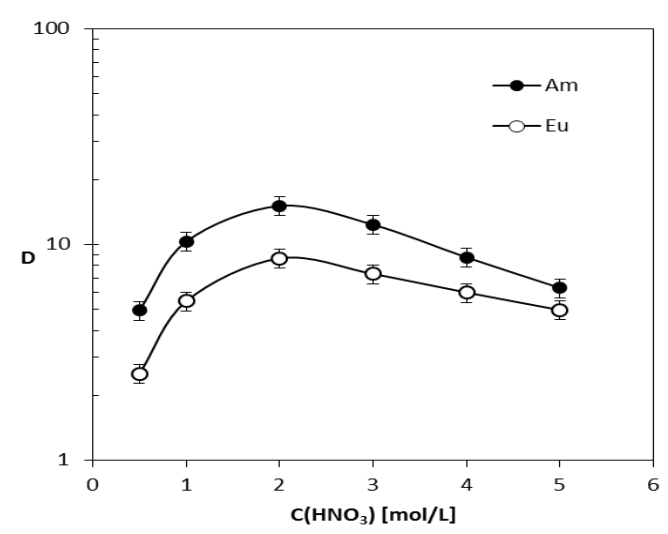

Figure 1 Extraction of $\mathrm{Am}(\mathrm{III})$ and $\mathrm{Eu}(\mathrm{III})$ by $0.1 \mathrm{~mol} / \mathrm{L}$ CMPO dissolved in BK-1 from $\mathrm{HNO}_{3}$ solutions.

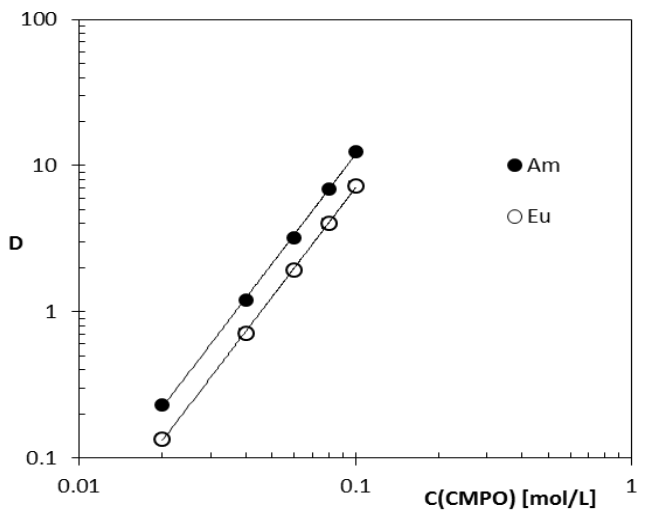

Figure 2. Extraction of Am(III) and Eu(III) by CMPO dissolved in BK-1 from 3 mol/L $\mathrm{HNO}_{3}$. 


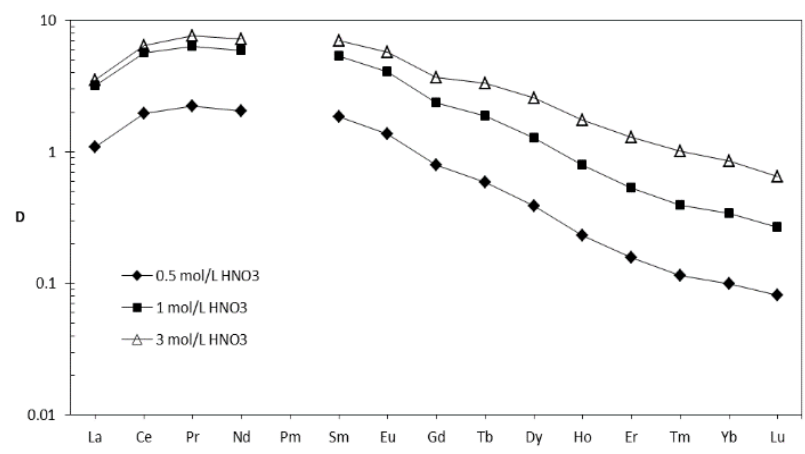

Figure 3. Extraction of lanthanides by $0.1 \mathrm{~mol} / \mathrm{L} \mathrm{CMPO}$ dissolved in $\mathrm{BK}-1$ from $\mathrm{HNO}_{3}$ solutions.

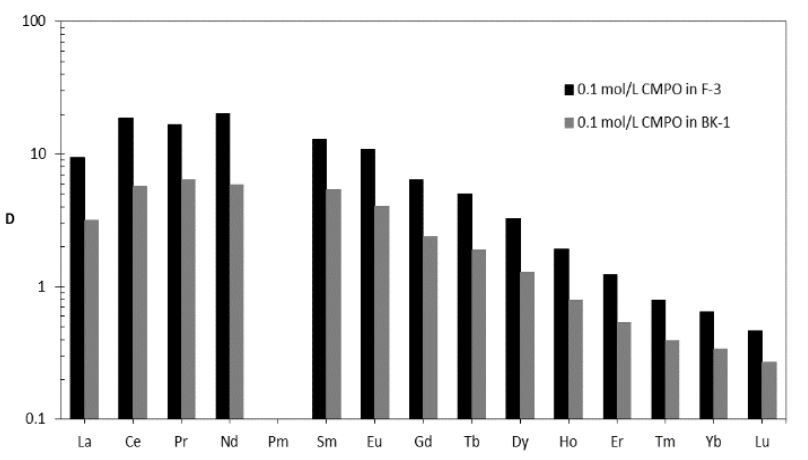

Figure 4. Extraction of lanthanides by $0.1 \mathrm{~mol} / \mathrm{L} \mathrm{CMPO} \mathrm{dissolved} \mathrm{in} \mathrm{BK-1} \mathrm{or} \mathrm{F-3} \mathrm{from} 1$ $\mathrm{mol} / \mathrm{L} \mathrm{HNO}_{3}$. 


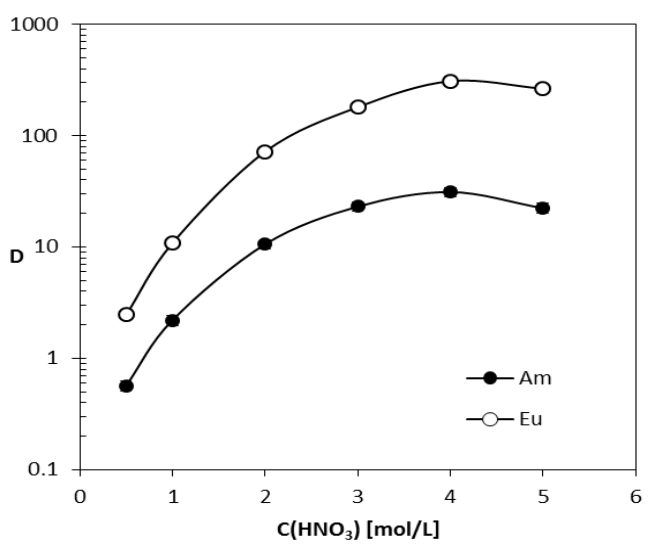

Figure 5. Extraction of $\mathrm{Am}(\mathrm{III})$ and $\mathrm{Eu}(\mathrm{III})$ by $0.1 \mathrm{~mol} / \mathrm{L}$ THDGA dissolved in BK-1 from $\mathrm{HNO}_{3}$ solutions.

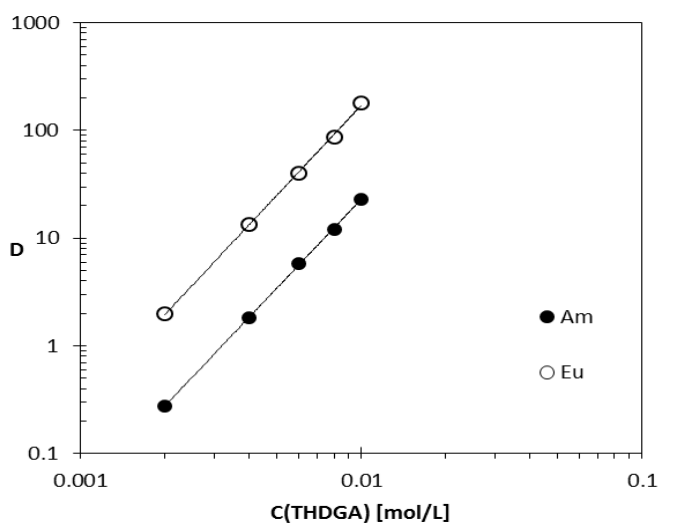

Figure 6. Extraction of Am(III) and Eu(III) by THDGA dissolved in BK-1 from 3 mol/L $\mathrm{HNO}_{3}$. 


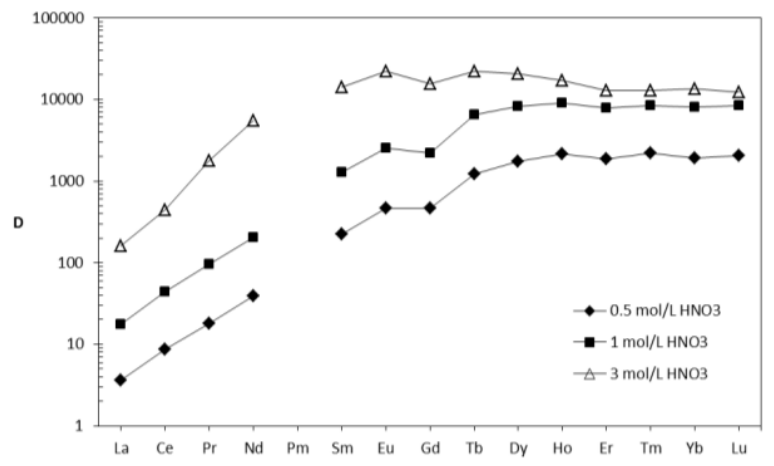

Figure 7. Extraction of lanthanides by 0.1 mol/L THDGA dissolved in $\mathrm{BK}-1$ from $\mathrm{HNO}_{3}$ solutions.

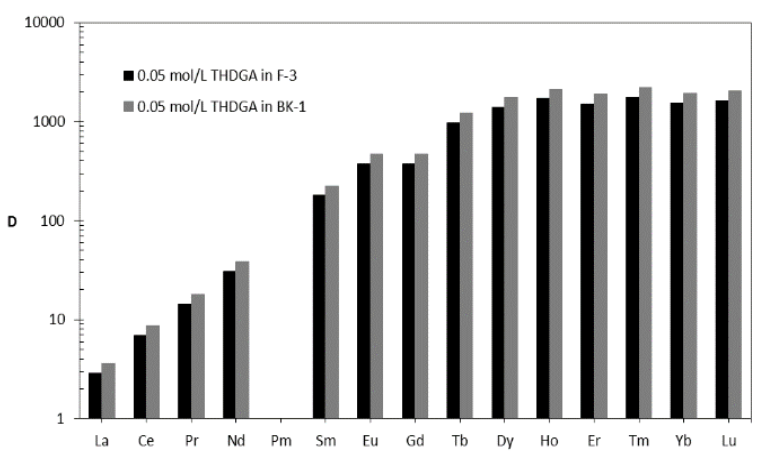

Figure 8. Extraction of lanthanides by 0.05 mol/L THDGA dissolved in BK-1 or F-3 from 0.5 $\mathrm{mol} / \mathrm{L} \mathrm{HNO}_{3}$. 


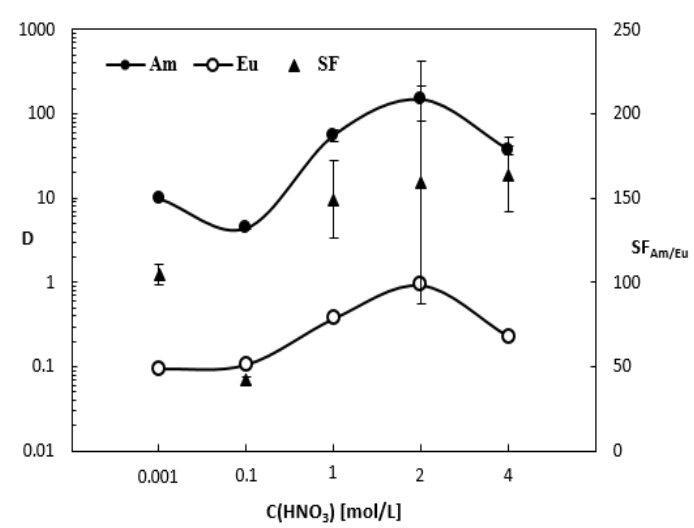

Figure 9. Extraction of $\mathrm{Am}(\mathrm{III})$ and $\mathrm{Eu}(\mathrm{III})$ by $4 \mathrm{mmol} / \mathrm{L}$ CyMe $4-\mathrm{BTBP}$ dissolved in BK-1 from $\mathrm{HNO}_{3}$ solutions (gamma measurements).

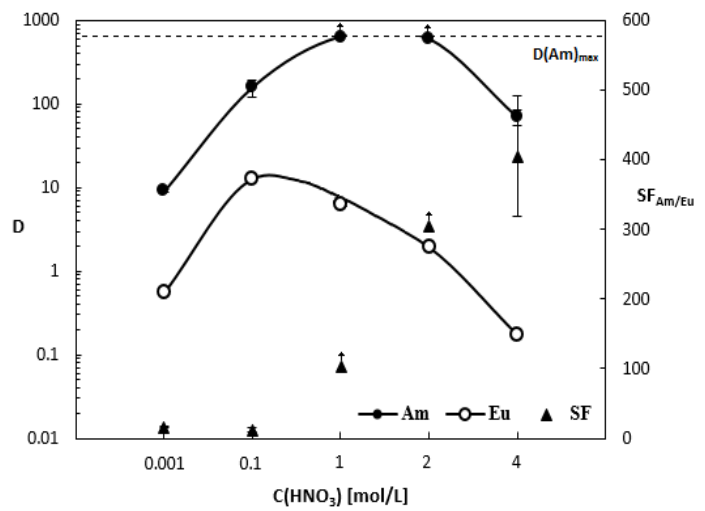

Figure 10. Extraction of $\mathrm{Am}(\mathrm{III})$ and $\mathrm{Eu}(\mathrm{III})$ by $4 \mathrm{mmol} / \mathrm{L}$ CyMe $4-\mathrm{BTPhen}$ dissolved in BK-1 from $\mathrm{HNO}_{3}$ solutions (gamma measurements). 


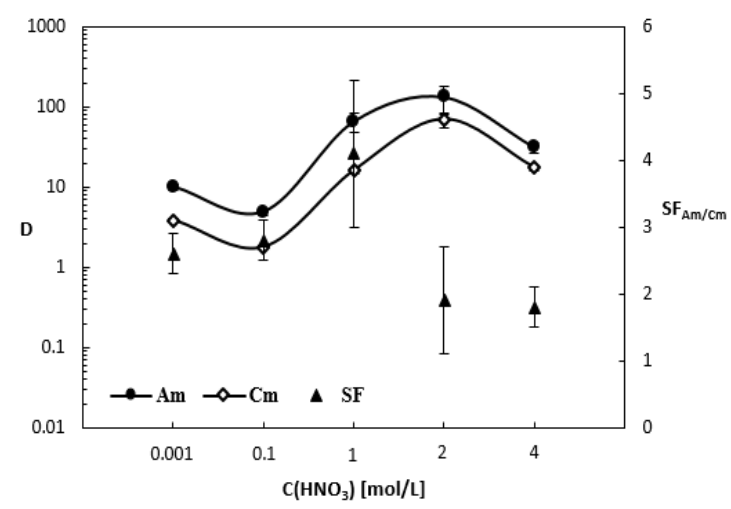

Figure 11. Extraction of Am(III) and Cm(III) by 4 mmol/L CyMe- $-\mathrm{BTBP}$ dissolved in BK-1 from $\mathrm{HNO}_{3}$ solutions (alpha measurements).

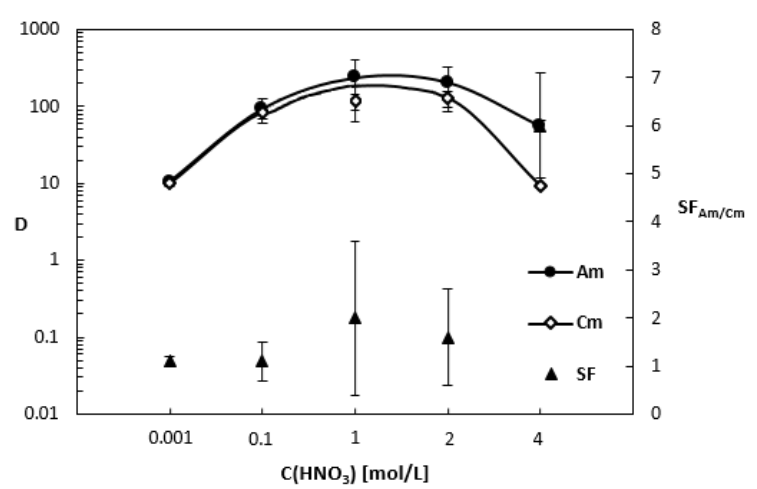

Figure 12. Extraction of $\mathrm{Am}(\mathrm{III})$ and $\mathrm{Cm}(\mathrm{III})$ by $4 \mathrm{mmol} / \mathrm{L} \mathrm{CyMe}_{4}-\mathrm{BTPhen}$ dissolved in BK1 from $\mathrm{HNO}_{3}$ solutions (alpha measurements). 


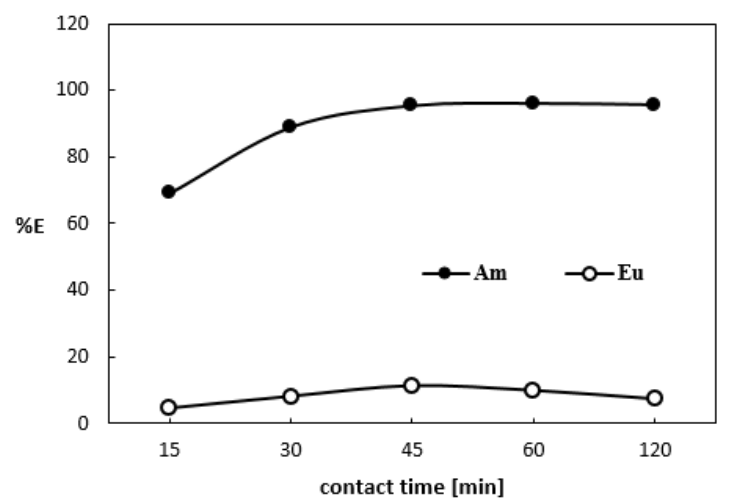

Figure 13. Kinetics of $\mathrm{Am}(\mathrm{III})$ and $\mathrm{Eu}(\mathrm{III})$ extraction from $1 \mathrm{~mol} / \mathrm{L} \mathrm{HNO}_{3}$ by $1 \mathrm{mmol} / \mathrm{L}$ $\mathrm{CyMe}_{4}-\mathrm{BTBP}$ in BK-1.

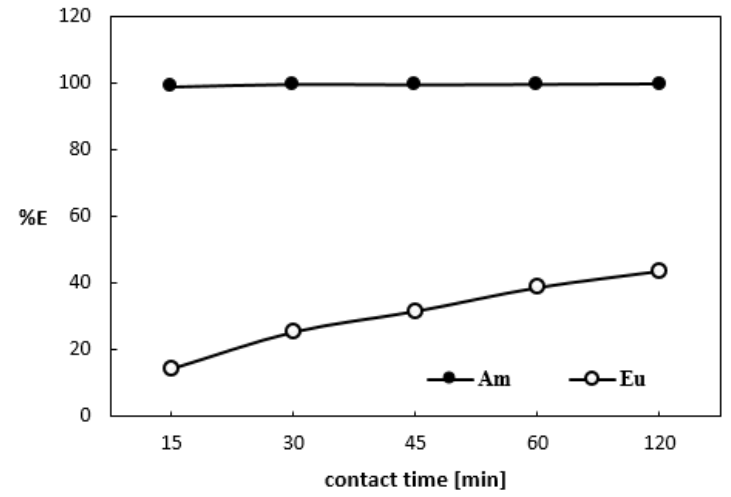

Figure 14. Kinetics of $\mathrm{Am}(\mathrm{III})$ and $\mathrm{Eu}(\mathrm{III})$ extraction from $1 \mathrm{~mol} / \mathrm{L} \mathrm{HNO}_{3}$ by $1 \mathrm{mmol} / \mathrm{L}$ $\mathrm{CyMe}_{4}-\mathrm{BTPhen}$ in BK-1. 